\title{
Oral Health-Related Quality of Life and Dental Caries Status Among Elderly People in Bantul Yogyakarta Indonesia: A Cross-Sectional Study
}

\author{
Sri Utami ${ }^{1, *}$ Yulianti $^{2}$ \\ ${ }^{1}$ Department of Dental Public Health, Dental School Program, Universitas Muhammadiyah Yogyakarta, Indonesia \\ ${ }^{2}$ Student of Dental School Program, Universitas Muhammadiyah Yogyakarta, Indonesia \\ ${ }^{*}$ Corresponding author. Email: sri.utami@umy.ac.id
}

\begin{abstract}
One of the indicators of poor oral health in older people is dental caries. Dental caries affects quality of life consisting physical, functional, social, and emotional welfare throughout each individual's life. This study aims to determine the correlation between dental caries status and quality of life among older people in Bantul Yogyakarta, Indonesia. It is an observational study using a cross-sectional design. Subjects of this study consisted of 69 older people in Bantul Yogyakarta Indonesia. The power of the test was $81.6 \%$. The dental caries status was measured using the DMFT index (WHO), and oral health-related quality of life was measured using GOHAI (WHO). The data analysis used was Spearman's correlation, at a 5\% significance level $(\alpha=0.05)$. The results showed that the DMF-T index mean value was very high (12.8) and GOHAI was low (43.7\%). There was a significant correlation between oral health-related quality of life and dental caries status among older people ( $\mathrm{p}=0.049, \mathrm{r}=0.238$ ). The higher the dental caries status was, the worse the oral health-related quality of life among older people in Yogyakarta, Indonesia would be.
\end{abstract}

Keywords: dental caries status, GOHAI, OHRQoL

\section{INTRODUCTION}

The number of older people in Indonesia is as many as 20 million people, equivalent to $8.03 \%$ of Indonesia's population, and in 2020 it will be 28.8 people, equivalent to $11.34 \%$ [1]. Disease disorders in the elderly can cause changes in their quality of life [2]. Health-related quality of life includes physical, functional, social and emotional well-being in individuals during their lifetime. Oral health status significantly affects the quality of life.

Poor oral health in the elderly is particularly evident with the number of missing teeth, dental caries and periodontal disease. Impaired oral health is common in the elderly, often causing pain, discomfort, loss of selfconfidence, acute and chronic infections, eating and sleeping disorders [3]. Bad oral conditions in the elderly, such as the number of missing teeth as a result of damaged or untreated trauma, will disrupt the function and activities of the oral cavity to affect nutritional status [4].

The most specific questionnaire for quality of liferelated to oral health in the elderly is GOHAI (Geriatric Oral Health Assessment Index). GOHAI instrument consists of 12 questions are grouped into 3 dimensions related to oral health; physical, psychosocial functions, and pain or discomfort [5].

\section{MATERIAL AND METHODS}

This study was an observational study with a crosssectional design and approved by the Research Ethics Committee of Universitas Muhammadiyah Yogyakarta. Participants in the study were informed concerning the ethical aspects and voluntarily signed the free and informed consent form. Participants were 69 elderly in Bantul Yogyakarta, aged over 60 years old. The power of the test was $81.6 \%$. The sampling technique used was total sampling.

The first stage of the study was to collect data on dental caries status using the DMF-T index by one examinator, with Kappa Coefficient intra-rater reliability, which was $100 \%$. Assessment of the quality of life used the Geriatric Oral Health Assessment Index (GOHAI). It translated into the Indonesian version and tested the validity and reliability $(\alpha=0.744)$. The GOHAI instrument consisted of 12 question items grouped into 3 dimensions related to oral health, physical, psychosocial functions, and pain or discomfort. The complete data were analyzed using Spearman's correlation analysis to determine the relationship between dental caries status and Oral Health-Related Quality of Life, at a 5\% significance level $(\alpha=0.05)$. 


\section{RESULT}

The highest mean value of the DMF-T index was 16.00 at 74 years. Based on the WHO, the mean value of the DMF-T index was very high. Of all participants, 51 $(73.91 \%)$ were female, with a mean value of DMF-T index 14.33 and $18(26.80 \%)$ were male, with a mean value of DMF-T index 11 .

Table 1. Mean Value of DMF-T Index

\begin{tabular}{llll}
\hline Characteristic & $\mathrm{N}(\%)$ & $\begin{array}{l}\text { Total } \\
\text { DMF-T }\end{array}$ & $\begin{array}{l}\text { Mean } \\
\text { DMF-T }\end{array}$ \\
\hline Age (Year) & & & \\
\hline $60-64$ & $8(11.60)$ & 93 & 11.62 \\
\hline $65-74$ & $58(84.05$ & 795 & 13.70 \\
\hline$>74$ & $3(4.34)$ & 48 & 16.00 \\
\hline Gender & & & \\
\hline Male & $18(26.08)$ & 205 & 11.38 \\
Female & $51(73.91)$ & 731 & 14.33 \\
\hline
\end{tabular}

Table 2. Mean Value of DMF-T based on WHO'S Criteria

\begin{tabular}{llllll}
\hline $\mathrm{N}$ & D-T & M-T & F-T & $\begin{array}{l}\text { Mean } \\
\text { DMF-T }\end{array}$ & $\begin{array}{l}\text { WHO'S } \\
\text { Criteria }\end{array}$ \\
\hline 69 & 3.8 & 9 & 0 & 12.8 & Very high \\
\hline
\end{tabular}

The worst or highest score of GOHAI was $21(30.43 \%)$ at age 65-74 years old. Females had the highest score, which was a moderate score of GOHAI (30.43\%). All participants had a good score of GOHAI (23.18\%), moderate score $(33.33 \%)$ and poor score $(43.47 \%)$.

Data analysis to determine the correlation between dental caries status and Oral Health-Related Quality of Life was Spearman's test at a 5\% significance level $(\alpha=0.05)$. It can be seen in Table 5 that the p-value was 0.049 (p $<0.05$ ), it can be concluded that there was a significant correlation between dental caries status and Oral HealthRelated Quality of Life. The higher the dental caries status was, the worse the oral health-related quality of life would be.

Table 3. GOHAI Score based on Age and Gender

\begin{tabular}{|l|l|l|l|}
\hline \multirow{2}{*}{ Characteristic } & \multicolumn{3}{|c|}{ Characteristic } \\
\cline { 2 - 4 } & Good n(\%) & \multicolumn{1}{|c|}{$\begin{array}{c}\text { Moderate } \\
\mathrm{n}(\%)\end{array}$} & Poor n(\%) \\
\hline Age (year) & & & \\
\hline $60-64$ & $10(14.49)$ & $1(1.44)$ & $7(10.14)$ \\
\hline $65-74$ & $6(8.69)$ & $18(26.08)$ & $21(30.43)$ \\
\hline$>74$ & $2(2.89)$ & $1(1.44)$ & $3(4.34)$ \\
\hline Gender & & & $10(11.2)$ \\
\hline Female & $20(28.98)$ & $21(30.43)$ & $12(17.39)$ \\
\hline Male & $3(4.34)$ & $3(4.34)$ & \\
\hline Total(N) & & & $30(43.47)$ \\
\hline 69 & $16(23.18)$ & $23(33.33)$ & \\
\hline
\end{tabular}

Table 4. Result of Spearman's Test

\begin{tabular}{|l|l|l|}
\hline & & GOHAI \\
\hline Dental caries status & $\mathrm{r}$ & 0,238 \\
\hline & $\mathrm{p}$ & 0,049 \\
\hline & $\mathrm{N}$ & 69 \\
\hline
\end{tabular}

\section{DISCUSSION}

The majority of dental caries in the elderly is root caries. The DMF-T index was measured through direct clinical examination, while the GOHAI index was measured using a questionnaire. The higher the score is, the more severe the quality of life will be. The higher the DMF-T value is, the worse the dental caries status will be. The highest mean DMF-T was 16 at age> 74 years old, while the lowest mean DMF-T was 10.75 at age 60-64 years old. Based on these data, it showed that DMF-T tended to occur at the age of more than 74 years old, where the possibility of physical, psychological, and biological abilities had significantly decreased from the age below. This condition showed that the oral cavity condition was also getting worse with the high DMF-T mean value at that age.

The increasing age indicated, the higher the prevalence of dental caries and dental caries decay (DMF$\mathrm{T})$. The older the age is, the greater the DMF-T value will be. It is understandable because of public awareness, which was due to the lack of knowledge on the importance of dental health [4]. The Mean DMF-T value in women was higher than men. It was probably due to the attitudes and behavior who attended to pay more attention to household activities such as cooking, trying different kinds of food (dietary factors), nutritional factors, hormonal factors and physical conditions that were far different from men. The DMF-T value may also be influenced by knowledge and attention from the surrounding environment by teaching and supervising daily activities in maintaining oral hygiene, both by themselves and by other people in the environment where the elderly lived.

Older women preferred to eat sweet foods and contained lots of sugar. Consuming excess sugar in terms of dietary factors frequently carried out by women causing an acidic condition in the mouth [4]. Knowledge of oral health is essential for the formation of actions in maintaining dental and oral hygiene. Maintaining oral hygiene in old age is essential to improve general health [6]. Based on questionnaire data from the seven dimensions of quality of life, the frequently found dimension was physical pain, while the least was the delay dimension. Men had a worse overall quality of life score than women and 70-79-year-old people had the worst quality of life score. According to researchers this was likely due to increasing age such as a physical decline, mental changes (appearance, perception and reduced psychomotor skills), and psychosocial changes of life such as loneliness, economic changes, chronic illness and 
disability, loss of strength and physical stability [7]. Systemic disease may also cause another factor that causes poor quality of life in the elderly.

The elderly aged over 65 years old, complained about not being able to eat comfortably. The age over 70 was likely to have a worse quality of life than elderly people less than 70 years old [8]. The distribution of dental caries status based on the quality of life showed that there was a significant relationship between dental caries status and the oral health quality of life in older people in Yogyakarta Indonesia. Adequate medical and dental care can reduce early morbidity and mortality, maintain functions and improve life quality. Dental caries causes pain spontaneously; if dental caries is not resolved immediately, there will be an abscess, which will cause extreme pain, which causes the tooth to be removed. Thus, mastication function does not run optimally and the quality of life is disturbed [9].

The average DMF-T value at age more than 70 was higher than the age of 60-69. The autonomic ability (autonomy) of the quality of life of the elderly aged 60-69 years old was significantly associated with the DMF-T index. Caries is very influential on the overall quality of life without being to be influenced by age and gender. One of the precautionary measures and recommendations that can be taken is to improve the level of oral health, one of which can be done by participating in counseling services by dentists carried out during routine visits to the dentist at least every 6 months [10].

\section{CONCLUSION}

There was a significant correlation between dental caries status and Oral Health-Related Quality of Life in the older people in Bantul Yogyakarta, Indonesia. The higher the dental caries status is, the worse the quality of life of the elderly. The dental caries status in the elderly will be, according to WHO, a very high category. The oral helathrelated quality of life is poor. Poor oral health-related quality of life status was mostly found at 65-74 years old $(30.43 \%)$ and male elderly $(17.39 \%)$. Caries is very influential factor on the overall quality of life without being influenced by age and gender. One of the precautionary measures and recommendations that can be taken is to improve oral health. One of which can be done by participating in counseling services by dentists carried out during routine visits to the dentist at least every 6 months. Health Officers have to continue to develop programs related to promotional and preventive efforts related to oral health to improve the quality of life, especially for the elderly.

\section{AUTHORS' CONTRIBUTIONS}

Study conception and design: Sri Utami, data collection: Sri Utami and Yulianti, analysis and interpretation of result: Sri Utami, draft manuscript and preparation: Sri Utami and Yulianti. All authors reviewed the results and approved the final version of the manuscript.

\section{ACKNOWLEDGMENTS}

We are thankfull to the participants who took part in this study.

\section{REFERENCES}

[1] Central Bureau of Statistics, Elderly Population Statistics, Jakarta Indonesia, 2008, pp. 96-101.

[2] M. Power, and S. Smith, The WHOQOL-OLD Module-manual, WHO, 2006, pp. 5-7.

[3] L. Followfield, Health Economics: What is Quality of Life, 2nd ed., Hayward Medical Communication Group Ltd., London, 2009, pp. 1-3.

[4] P. Holm-Pedersen, A. Walls, J. Ship, Textbook of Geriatric Dentistry, Third Edition, Willey Blackwell, 2015, pp. 131-135.

[5] D. Agustina, L. Hanindriyo, E. Widita, R, Widyaningrum, The correlation between occurrence of dental caries and oral health-related quality of life (OHRQoL) of elderly population in Yogyakarta Special Region, 2018, pp. 191-200. DOI: http://dx.doi.org/10.19106/JMedSci00500220180

[6] M. MacEntee, Quality of Life as an Indicator of Oral Health in Older People, J Am Dent Assoc, 2007, 138 (1): $47 \mathrm{~S}-52 \mathrm{~S}$.

[7] JW. Little, DA. Falace, CS Miller, NL. Rhodus, Dental management of medically compromised patient. 6th ed. Missouri: Mosby, Inc., St Louis, Missouri, 2002.

[8] D. Locker, F. Allen, What do Measures of 'Oral Health-Related Quality of Life' measure?, Community Denstitry and Oral Epidemiology, 2007, 3(5): 401-411.

[9] F. Caglayan, O. Altun, D. Kaya, A. Yilmas, Correlation Between Oral Health- Related Quality of Life (OHRQOL) and Oral Disorder In a Turkish Patient Population. Oral Medicine and Pathology, 2009, 1(11): 573-578.

[10] D. Ozdemir, Dental Caries and Preventive Strategies. Journal Of Education And Instructional Studies, 2014, 4(2): 4-9. 